\title{
Upper airway obstruction caused by primary lymphoplasmacytic lymphoma of the retropharyngeal space: a case report
}

\author{
Chinyere N. Asoegwu ${ }^{1,2^{*}}$ (D), Okezie O. Kanu ${ }^{1}$ and Clement C. Nwawolo ${ }^{1,2}$
}

\begin{abstract}
Background: Primary malignant tumours of the retropharyngeal space are rare with only a few case reports in the literature. Lymphoplasmacytic lymphoma is a rare subtype of non-Hodgkin lymphoma and is very rarely found as a primary tumour of the retropharyngeal space.

Case presentation: We report the case of progressive upper airway obstruction in a 49-year-old male caused by a primary malignant tumour of the retropharyngeal space lymph nodes. He had an emergency tracheostomy to relieve the upper airway obstruction followed a week later by an elective surgical excision of the tumour via the trans-cervical route. A mixed population of lymphocytes, with a marked presence of Dutcher bodies, was noted on histopathology and positive CD20 on immunohistochemistry, confirming the lymphoplasmacytic lymphoma of the retropharyngeal space. The watchful waiting treatment method for the lymphoma was employed for him since he had no symptoms relating to lymphoma and no serum Waldenström's macroglobulinemia. He has remained symptom-free 3 years post-surgery.

Conclusion: Primary malignant tumours involving the retropharyngeal space lymph nodes are very rare. They can rarely grow to a size huge enough to cause obstructive upper aerodigestive symptoms. Primary lymphoma of the retropharyngeal space should be considered in the diagnosis of the tumours involving the retropharyngeal space lymph nodes. Excisional biopsy is important to obtain tissue for histopathological diagnosis and the relief of upper aerodigestive tract obstruction when present.
\end{abstract}

Keywords: Lymphoplasmacytic lymphoma, Retropharyngeal space tumour, Dyspnea, Lymph nodes, Case report

\section{Background}

Lymphoplasmacytic lymphoma (LPL) is a rare, slowgrowing tumour of the lymphoid tissue that is usually associated with a serum IgM paraprotein, known as Waldenström macroglobulinemia (WM) [1]. Rarely, a few cases present with IgG, IgA or without a monoclonal protein [2]. It is a rare subtype of non-Hodgkin lymphoma. The common sites of non-Hodgkin lymphoma in the head and neck include the cervical lymph nodes, the

\footnotetext{
* Correspondence: casoegwu@unilag.edu.ng

'Department of Surgery, Faculty of Clinical Sciences, College of Medicine, University of Lagos, Lagos, Nigeria

²Department of Ear, Nose and Throat Surgery, Lagos University Teaching Hospital, Idi Araba, Lagos, Nigeria
}

\section{Springer Open}

Waldeyer's ring, salivary gland, paranasal sinuses, orbit, maxilla and the mandible [3]. Retropharyngeal space (RPS) lymph nodes are commonly involved in infectious diseases of the pharynx. Metastatic involvement of the RPS by squamous cell carcinoma of the nasopharynx is common [4]. However, primary malignant tumours of the RPS are rare. A few cases of lymphoma involving the RPS lymph nodes have been reported $[5,6]$. These were mainly Burkitt's lymphoma, non-Hodgkin lymphoma and Hodgkin lymphoma.

This case report documents an adult patient who presented with a severe upper airway obstruction caused by a very rare subtype of non-Hodgkin's lymphoma as a primary tumour of the RPS. 


\section{Case presentation}

A 49-year-old male factory worker presented with a history of 6 months of progressive dyspnea. There was a preceding/associated history of snoring, noisy breathing, sleep-disordered breathing, progressive neck swelling and weight loss of 2-year duration. There was no associated cough, dysphagia, odynophagia or fever. He developed severe breathing difficulty a week before the presentation. He was brought into the emergency department on his first visit to our facility in imminent upper airway obstruction. On clinical examination, he was not pale, icteric or febrile but had severe stridor. Examination of the oropharynx showed a huge posterior pharyngeal wall bulge extending from above the soft palate to the hypopharynx. There was a left-sided neck swelling extending from the level of the thyroid cartilage to the root of the neck and from the midline to the posterior border of the sternocleidomastoid muscle laterally. The swelling was soft, compressible and there was no differential warmth or attachment to the skin or underlying structures. A clinical diagnosis of imminent upper airway obstruction secondary to retropharyngeal space tumour was made at presentation. He had an emergency tracheostomy for the relief of the upper airway obstruction the same day.
His complete blood count was normal. He did a CT scan of the neck which showed mixed density mass in the retropharyngeal space extending from the level of the foramen magnum to the second thoracic vertebral body inferiorly and extending laterally into left the parapharyngeal space with heterogeneous post-contrast enhancement. There was associated anterior displacement, bowing and compression of the pharyngeal, laryngeal and tracheal airway and the oesophagus. No invasion of the walls or metastatic deposit in the cervical spine (Fig. $1 \mathrm{~B}$ and $\mathrm{C}$ ). Radiologic diagnosis of upper airway obstruction secondary to retropharyngeal space lymphadenopathy with abscess to rule out tumour involving the lymph nodes was made. An MRI was requested to further assess the tumour but the patient could not afford it. Elective surgical excision of the mass followed 1 week after presentation via the trans-cervical route. Finding at surgery was a multi-lobulated mass with fatty, muscular, fibrous and mixed consistency areas. The tumour was attached to the pharynx, thyroid cartilage, trachea and oesophagus, but not adherent to the great vessels (Fig. $2 \mathrm{~A}$ and B). It measured $24.5 \times 7.5 \times 4.2$ $\mathrm{cm}$, weighed $350 \mathrm{~g}$ and was sent for histopathology. Symptoms of upper airway obstruction resolved postsurgery and he was decannulated 5 days post-surgical excision.
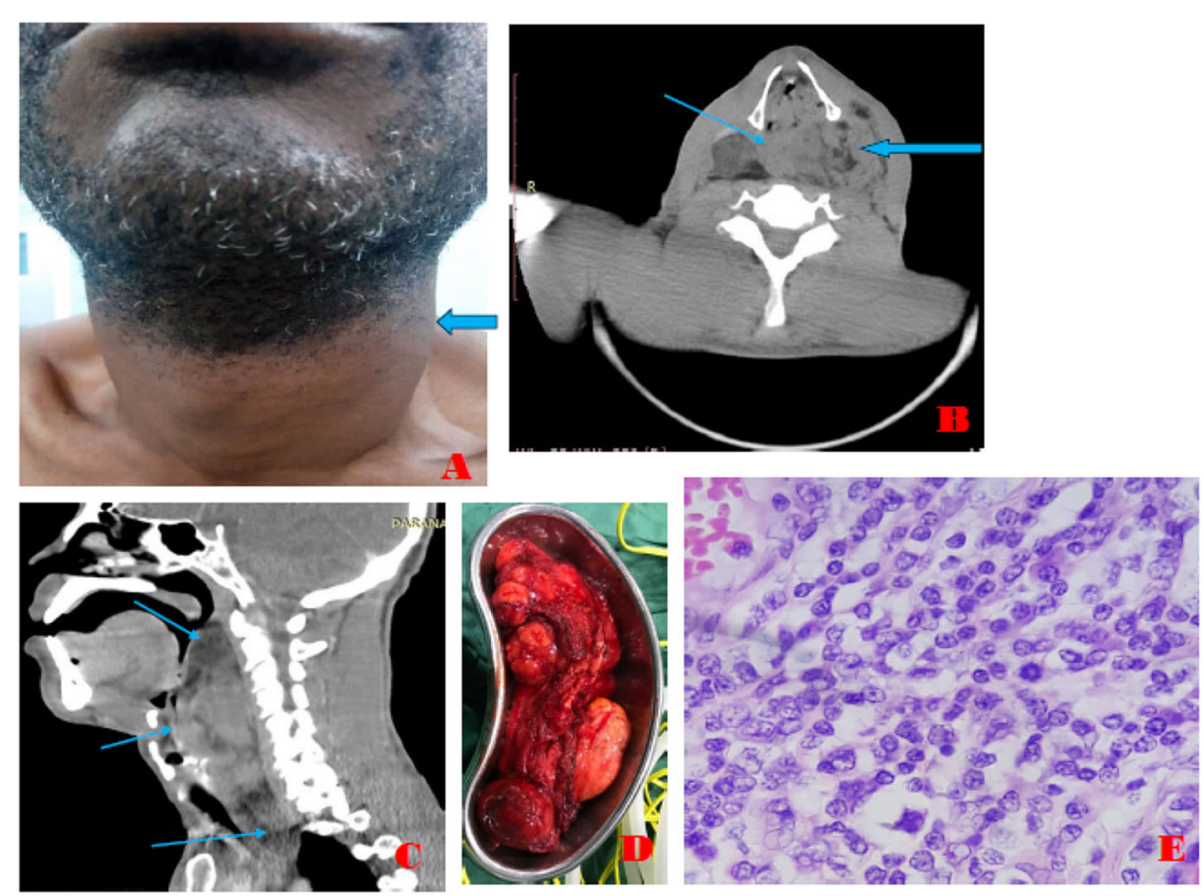

Fig. 1 A Left neck swelling. B Axial neck CT scan showing huge retropharyngeal mass compressing and narrowing the airway and extending into the left parapharyngeal space. C Sagittal view showing lobulated isodense mass from the skull base to the superior mediastinum compressing the upper aerodigestive tract. D Post-operative specimen of multi-lobulated mass with fatty, muscular, fibrous and mixed consistency areas weighing $350 \mathrm{~g}$. E Microhistograph showing numerous Dutcher bodies 

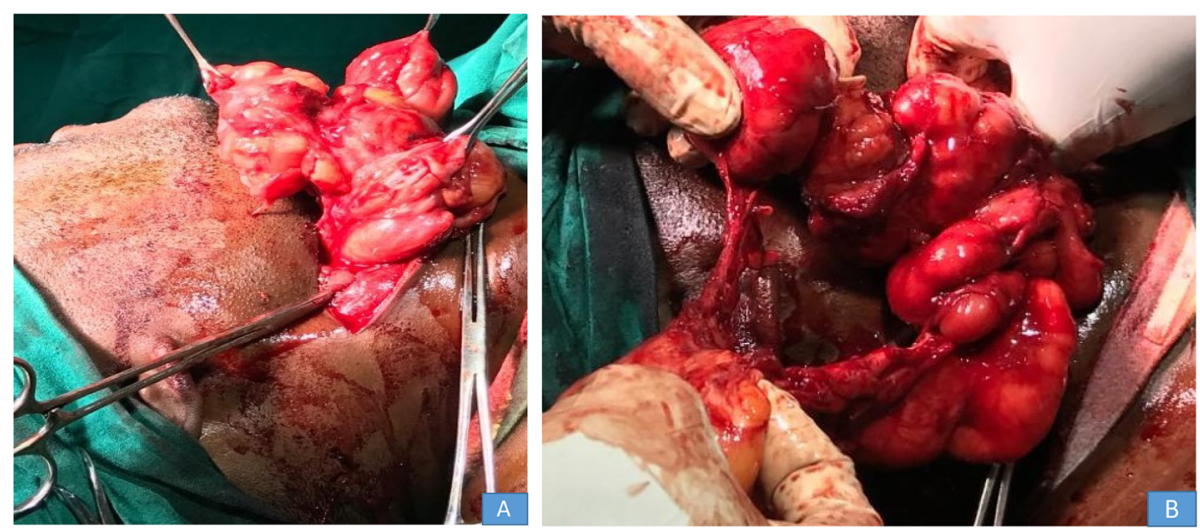

Fig. $2 \mathbf{A}$ and $\mathbf{B}$ Intra-operative pictures

The histopathology report showed fibro-adipose stroma containing diffuse sheets of a mixed population of lymphocytes, with a marked presence of Dutcher bodies and a diagnosis of lymphoplasmacytic lymphoma. This was confirmed by immunohistochemistry where the lymphocytes were CD20 positive but were CD5, CD10 and IgM negative. The definitive diagnosis of stage 1 lymphoplasmacytic lymphoma was made.

We adopted watchful waiting for this patient with negative serum Waldenström's macroglobulinemia. The patient has been very satisfied with the care he received as he has all his symptoms relieved and has returned to his normal life. He has remained symptom-free 3 years post-surgery.

Patient's written consent for publication was obtained.

\section{Discussion}

RPS lymphadenopathy is commonly associated with deep neck space infection and metastasis from squamous cell carcinoma of the nasopharynx and pharyngeal wall. Occasionally, there could also be metastasis from squamous cell carcinoma of the supraglottic larynx and cervical oesophagus. Primary malignant tumours of the RPS are rare and more so with those involving the lymph nodes. Lymphoplasmacytic lymphomas are rare tumours belonging to non-Hodgkin lymphoma and account for only $1-2 \%$ of the hematologic cancers [7]. This is the first report of lymphoplasmacytic lymphoma involving the retropharyngeal space in sub-Saharan Africa.

LPL is a sub-type of non-Hodgkin lymphoma that is indolent. Symptoms and signs of LPL are mainly from bone marrow infiltration and high blood paraprotein (Igm) level. Patients may be asymptomatic or present with anaemia, neutropenia and thrombocytopenia, weight loss, fever, numbness of extremities, lymphadenopathy, hepatomegaly, splenomegaly and amongst others
[2]. Adult non-Hodgkin lymphoma is classified as stage 1 when involving one lymphatic area (lymph node, tonsils, thymus, spleen) and stage $1 \mathrm{E}$ when an organ or area outside the lymph nodes is involved [2].

Retropharyngeal space (RPS) is a potential space that is related anteriorly to the upper aerodigestive tract, laterally to the para-pharyngeal space, posteriorly to the prevertebral space and inferiorly to the mediastinum. The suprahyoid portion of the RPS contains lymph nodes and adipose tissue whilst the infra-hyoid portion contains adipose tissue only. The presenting symptoms of RPS tumours usually result from compression of the surrounding structures and include dysphagia, globus sensation, noisy respiration, snoring, dyspnea, obstructive sleep apnea, hoarseness and painless neck mass $[8,9]$.

The index case presented with a history of progressive dyspnea with an associated history of snoring, noisy breathing, obstructive sleep apnea, neck swelling and weight loss. On clinical examination, the patient had severe stridor, a huge posterior pharyngeal wall bulge extending from the nasopharynx to the hypopharynx on oropharyngeal examination and a neck swelling that was more to the left.

The presenting symptoms and signs in RPS tumours depend on the rate of growth, size and tumour location in the RPS. Symptoms, in this case, were mainly of the upper airway obstruction resulting from upper airway compression caused by the giant size of the tumour as evidenced by the huge posterior pharyngeal wall bulge and the neck swelling, and the location of the tumour through the entire length of the RPS. There was the absence of upper digestive tract obstructive symptoms despite the size/extent and location of the tumour, and the oesophageal compression reported in the $\mathrm{CT}$ scan. This could be attributed to the compressible nature of the tumour. The weight 
Table 1 Case reports of LPL in the neck and chest

\begin{tabular}{|c|c|c|c|c|c|c|c|c|}
\hline $\begin{array}{l}\text { Reference } \\
\text { reported/ year }\end{array}$ & $\begin{array}{l}\text { Age/ } \\
\text { Sex }\end{array}$ & $\begin{array}{l}\text { Duration of } \\
\text { symptom }\end{array}$ & Major symptoms & $\begin{array}{l}\text { Location in the } \\
\text { RPS }\end{array}$ & $\begin{array}{l}\text { Histology } \\
\text { report }\end{array}$ & Surgical type & $\begin{array}{l}\text { CTx } \\
\text { RTx }\end{array}$ & $\begin{array}{l}\text { Follow } \\
\text { up }\end{array}$ \\
\hline $\begin{array}{l}\text { Bakari A et al } \\
2013[6]\end{array}$ & $\begin{array}{l}\text { 7yrs/ } \\
M\end{array}$ & 4 Months & Nasal blockage, neck swelling & Not stated & $\begin{array}{l}\text { Burkitt's } \\
\text { lymphoma }\end{array}$ & Trans-oral biopsy & $C T x$ & $\begin{array}{l}\text { Not } \\
\text { stated }\end{array}$ \\
\hline $\begin{array}{l}\text { Noguchi S et al } \\
2013 \text { [19] }\end{array}$ & $\begin{array}{l}54 y r s / \\
M\end{array}$ & 3 years & Not stated & $\begin{array}{l}\text { Para tracheal } \\
\text { mediastinum }\end{array}$ & LPL & $\begin{array}{l}\text { Resection via } \\
\text { thoracotomy }\end{array}$ & $C T x$ & 3 years \\
\hline $\begin{array}{l}\text { Adachi Y et al } \\
2020 \text { [20] }\end{array}$ & $\begin{array}{l}60 y r s / \\
M\end{array}$ & 5 years & Dry cough, dyspnea & $\begin{array}{l}\text { Mediastinum \& } \\
\text { lung }\end{array}$ & $\begin{array}{l}\text { LPL \& } \\
\text { Amyloidosis }\end{array}$ & $\begin{array}{l}\text { Biopsy via } \\
\text { thoracotomy }\end{array}$ & $\begin{array}{l}\text { Not } \\
\text { stated }\end{array}$ & $\begin{array}{l}\text { Not } \\
\text { stated }\end{array}$ \\
\hline Present case & $\begin{array}{l}\text { 49yrs/ } \\
M\end{array}$ & 2 years & $\begin{array}{l}\text { Dyspnea, snoring, neck } \\
\text { swelling, weight loss }\end{array}$ & $\begin{array}{l}\text { Entire length of } \\
\text { the RPS }\end{array}$ & $L P L$ & $\begin{array}{l}\text { Trans-cervical } \\
\text { excision }\end{array}$ & None & 3 years \\
\hline
\end{tabular}

CTx chemotherapy, RTx radiotherapy

loss in the patient can therefore be attributed to the lymphoma. The history of 2-year duration of the disease probably represents the time the tumour was large enough to cause symptoms and may not represent a fast growth rate for the tumour.

RPS cannot be thoroughly assessed clinically without radiological imaging. CT scan and MRI scan are the recommended modalities for the assessment of the RPS. MRI is the modality of choice for the detection of retropharyngeal space nodal involvement [10]. It has a better spatial resolution, able to identify smaller nodes, diagnose nodal metastases at an early stage and distinguish nodes from the primary tumour in the adjacent nasopharynx more than a CT scan [11]. The CT scan helped arrive at the non-definitive diagnosis in this case and that was what the patient could afford. Surgical excision is the mainstay of treatment for primary retropharyngeal tumours causing obstructive symptoms. Approaches for the surgical excision of RPS tumours include trans-oral and trans-cervical. The choice of approach often depends on the size and site of the tumour. Trans-oral is the preferred approach for smaller tumours that are accessible via the oropharynx [12]. The trans-cervical approach is used for relatively large tumours and tumours that cannot be accessed via the oropharynx because of their location $[8,9]$.

The commonest primary RPS tumour in the literature is lipoma. This has been mainly as case reports. Ozawa et al. in 2007 reported a case of RPS liposarcoma, and in their review of the literature, they cited 7 other case reports [13]. Since then, a few more cases have been reported [14-16]. Primary synovial sarcoma and malignant schwannoma of the RPS have also been reported [17, 18]. Very few cases of primary RPS lymphoma have been reported in literature. These include a case of Burkitt's lymphoma and two cases of LPL of the mediastinum [6, 19, 20]. The details of their presentation and management are summarised in Table 1.

The treatment for LPL ranges from watchful waiting, chemotherapy, plasmapheresis, biological therapy and stem cell transplant rarely. The 5 years and above survival is $87 \%, 68 \%$ and $36 \%$ for low, intermediate and high-risk groups respectively [21]. Our patient had his upper airway obstruction relieved by an emergency tracheostomy at presentation. Subsequently, the RPS tumour was excised via a left trans-cervical incision because of its size with full relief of his symptoms. Following the confirmation of his diagnosis, the choice of treatment for the LPL was watchful waiting since the systemic symptoms relating to lymphoma was few.

\section{Conclusions}

Upper airway obstruction resulting from a primary malignant tumour of the RPS is rare, and lymphoplasmacytic lymphoma of the RPS is very rare. The presenting symptoms depend on the size, rate of growth, consistency, location in the RPS and the stage of the tumour. The relevant investigations are $\mathrm{CT}$ scans and preferably MRI scans. Excisional biopsy is required to relieve obstructive symptoms and to obtain tissue for definitive diagnosis by histopathology and immunohistochemistry. Further treatment is directed at the primary pathology.

\section{Abbreviations}

LPL: Lymphoplasmacytic lymphoma; RPS: Retropharyngeal space; WM: Waldenström macroglobulinemia; IgM: Immunoglobulin M;

$\mathrm{CT}$ : Computerised tomography; MRI: Magnetic resonance imaging; CTx: Chemotherapy; RTx: Radiotherapy

\section{Acknowledgements}

Not applicable

\section{Authors' contributions}

CNA was involved in the conceptualisation, design, and drafting of the manuscript. OOK was involved in the literature search and draft revision. $\mathrm{CCN}$ revised draft substantively and approved submitted version. All authors read and approved final manuscript.

\section{Funding}

None received

Availability of data and materials Not applicable 


\section{Declarations}

Ethics approval and consent to participate

Not applicable

\section{Consent for publication}

Written consent obtained from study participant

\section{Competing interests}

The authors have no conflict of interest to declare.

Received: 10 July 2021 Accepted: 27 August 2021

Published online: 08 October 2021

\section{References}

1. Owen RG, Treon SP, Al-Katib A et al (2003) Clinicopathological definition of Waldenstrom's macroglobulinemia: consensus panel recommendations from the Second International Workshop on Waldenstrom's Macroglobulinemia. Semin Oncol 30:110-115

2. Varettoni M, Boveri E, Zibellini S et al (2019) Clinical and molecular characteristics of lymphoplasmacytic lymphoma not associated with an IgM monoclonal protein: a multicentral study of the Rete Ematologica Lombarda (REL) network. Am J Hematol 94:1193-1199

3. Wollner N, Mandall L, Filippa D (1990) Primary nasal - paranasal oropharyngeal lymphoma in the paediatric age group. Cancer 65:14381444

4. Ferlito A, Shaha AR, Rinaldo A (2002) Retropharyngeal lymph node metastasis from cancer of the head and neck. Acta Otolaryngol 122:556-560

5. Davis WL, Harnsberger HR, Smoker WR, Watanabe AS (1990) Retropharyngeal space: evaluation of normal anatomy and diseases with CT and MR imaging. Radiology 174(1):59-64

6. Bakari A, Ahmad BM, Mohammed GM, Abubakar TS (2013) Life threatening retropharyngeal Burkitt's lymphoma mimicking adenoid obstructive disease. Ann Nigerian Med 7:35-37

7. Castillo JJ, Ghobrial IM, Treon SP (2015) Biology, prognosis, and therapy of Waldenström macroglobulinemia. Cancer Treat Res 165:177-195

8. Asoegwu CN, Wakwe NA, Nwawolo CC (2021) Retropharyngeal space lipoma: an unusual cause of dysphagia. Int J Otorhinolaryngol Head Neck Surg 7:379-381

9. Namyslowski G, Scierski W, Misiolek M, Urbaniec N, Lange D (2006) Huge retropharyngeal lipoma causing obstructive sleep apnea: a case report. Eur Arch Otorhinolaryngol 263:738-740

10. Lam WWM, Chan YL, Leung SF, Metreweli C (1997) Retropharyngeal lymphadenopathy in nasopharyngeal carcinoma. Head Neck 9:176-181

11. Olmi P, Fallai C, Colagrande S, Giannardi G (1995) Staging and follow-up of nasopharyngeal carcinoma: magnetic resonance imaging versus computerized tomography. Int J Radiat Oncol Biol Phys 32:795-800

12. Akhtar J, Shaykhon M, Crocker J, D'Souza AR (2001) Retropharyngeal lipoma causing dysphagia. Eur Arch Otorhinolaryngol 258:458-459

13. Ozawa H, Soma K, Ito M, Ogawa K (2007) Liposarcoma of the retropharyngeal space: report of a case and review of literature. Auris Nasus Larynx 34:417-421

14. Navazo Eguía Al, Huelga Ruíz MA, Terán Santos J, Ruíz de la Parte A (2009) Retropharyngeal liposarcoma: apropos of a case of apnoeas and hypopnoea during sleep. Acta Otorrinolaringol Esp. 60:295-297

15. Vella O, Bequignon A, Comoz F, Babin E (2016) Retropharyngeal liposarcoma: A rare cause of dysphagia. Eur Ann Otorhinolaryngol Head Neck Dis. 133:429-430

16. Wang YB, Fan ZT, Zhang XL (2019) Well-differentiated liposarcoma of the retropharyngeal space: a case report. Lin Chung Er Bi Yan Hou Tou Jing Wai Ke Za Zhi 33:378-380 Chinese

17. Nadig SK, Love MH, Brooker DS, Hall SJ (2002) Synovial sarcoma in the retropharyngeal space. J Laryngol Otol. 116(3):224-226

18. Supiyaphun P, Snidvongs K, Shuangshoti S, Khowprasert C (1997) Malignant transformation in a benign encapsulated schwannoma of retropharyngeal space: a case report. J Med Assoc Thai. 80(8):540-546

19. Noguchi S, Yatera K, Jinbo M, Fukuda Y, Yamasaki K (2013) Case of primary lymphoplasmacytic lymphoma limited to the paratracheal mediastinum. J UOEH

20. Adachi Y, Takimoto T, Takeda M, Matsumoto K, Takeuchi N et al (2020) Lymphoplasmacytic lymphoma involving the mediastinum and the lung, followed by amyloidosis: A surgically and genetically proven case. Respiratory Medicine Case Reports 31:101313

21. Morel P, Duhamel A, Gobbi P et al (2009) International prognostic scoring system for Waldenstrom macroglobulinemia. Blood 113:4163-4170

\section{Publisher's Note}

Springer Nature remains neutral with regard to jurisdictional claims in published maps and institutional affiliations.

\section{Submit your manuscript to a SpringerOpen ${ }^{\circ}$ journal and benefit from:}

- Convenient online submission

- Rigorous peer review

- Open access: articles freely available online

High visibility within the field

- Retaining the copyright to your article

Submit your next manuscript at $\boldsymbol{\nabla}$ springeropen.com 